\title{
Experimental pulmonary reimplantation
}

\author{
K. M. SHAW AND N.A. BURTON \\ From the Department of Surgery, Trinity College, Dublin
}

During the course of an investigation of the effects of total pulmonary denervation, it was decided that nothing short of pneumonectomy and reimplantation of the lung would provide unequivocal evidence of total denervation. It was appreciated that the consequent interruption of the bronchial arterial supply to, and of the lymphatic drainage from, the lung might introduce factors sufficiently important to invalidate any positive conclusions about the function of the pulmonary nerves. It is the purpose of this paper to record our experience with pulmonary reimplantation combined, in some cases, with contralateral pneumonectomy.

Since first performed by Juvenelle, Citret, Wiles, and Stewart (1951) the operation of pulmonary reimplantation has been carried out in many centres, using a technique which has become more or less standardized.

The operation is performed on mongrel dogs under general anaesthesia with thiopentone sodium and gallamine triethiodide ('flaxedil'). They are ventilated at a constant rate and pressure using an 'Adelaide' respirator and a 2/1 nitrous oxide/oxygen mixture. A lung, usually the left, is mobilized completely, and the animal is heparinized with $2 \mathrm{mg}$. $/ \mathrm{kg}$. body weight. The lung is then resected together with a cuff of atrial wall that surrounds the insertion of the pulmonary veins. The lung is reimplanted by continuous suture with fine silk $(5 / 0)$ of atrium, pulmonary artery, and bronchus in that order. No repair of the bronchial arterial supply is possible owing to the small size of the bronchial arteries.

In our hands the lung is totally ischaemic for 60 to 90 minutes, and we have used local hypothermia in most cases. The present technique consists of perfusion of the isolated lung through its pulmonary artery with iced saline until the perfusate runs clear from the pulmonary veins (Nigro, Reimann, Mock, Fry, Benfield and Adams, 1963). The perfusate is preserved for transfusion and no other transfusion has been given. That hypothermia is not essential is shown by Blumenstock and Kahn (1961), who recorded normal recovery after total pulmonary ischaemia for up to two hours at normal temperature.

Despite a fairly extensive literature on the sub- iv ject of reimplantation and homotransplantation of $\vec{\infty}$ the lung, the function of the implanted lung has received little attention, with a few exceptions. 을 Yeh, Ellison, and Ellison (1962) recorded studies $\vec{r}$ of the blood gases and pulmonary artery pressures both before and after occlusion of the contralateral pulmonary artery by an intraluminal balloon. Their results showed a constant disturb- $\ddot{\mathscr{Q}}$ ance of oxygenation in the reimplanted lung. They considered that failure to survive contralateral pneumonectomy was due to retention of bronchial secretions. The original animal of Juvenelle was examined by bronchospirometry three years after operation and had a satisfactory ventilation and $\mathbb{Q}$ oxygen uptake (Portin, Rasmussen, Stewart, and $\overrightarrow{\vec{O}}$ Andersen, 1960). Linberg, Demetriades, Arm- $\frac{\circ}{3}$ strong, and Konsuwan (1961) carried out bronchospirometry on one animal and found a satisfactory oxygen uptake in the reimplanted lung. After contralateral pneumonectomy the oxygen uptake of $\overline{0}$ the reimplanted lung was $198 \mathrm{ml}$. $/ \mathrm{min}$. and the $\underset{x}{\stackrel{\nu}{x}}$ arterial oxygen saturation was $98 \%$ while $\frac{0}{\sigma}$ breathing $100 \%$ oxygen. The animal survived only six hours.

The pragmatic test of a lung's function is resection of the contralateral lung, a procedure for 0 which there is little recorded success. Blumenstock and Kahn (1961) had one survivor for seven days with apparently normal function, after which the animal was sacrificed. Hardin and Kittle (1954) 0 reported two survivors for six and nine days after $N$ homotransplantation and contralateral pneumon- N ectomy. Nigro et al. (1963) obtained three survivors on a single reimplanted lung by producing slow cicatrization of the contralateral bronchus. Alican and Hardy (1963) failed to obtain survivors $\stackrel{\oplus}{\rightarrow}$ after contralateral pneumonectomy, although two out of seven animals survived ligation of the con- $\bar{O}$ tralateral pulmonary artery. These authors noted $\mathbb{\Phi}$ a pattern of slow, deep respiration after contra- $\frac{\vec{\Phi}}{\mathbb{D}}$ lateral pneumonectomy, which they attributed to loss of respiratory reflexes, and they considered 
this disordered respiration to be a serious bar to survival. Most of their animals showed pulmonary oedema.

In brief, the rather general failure to obtain survivors beyond a few days on a single reimplanted lung has been attributed to the following main causes: (1) acute pulmonary hypertension, usually with pulmonary oedema ; (2) disturbance of oxygenation due to impaired diffusion; (3) retained bronchial secretions with atelectasis and pneumonia ; and (4) disordered respiration due to total pulmonary denervation.

\section{MATERIAL}

The present review does not include animals in which death from technical mishaps renders them irrelevant to the discussion. Apart from technical failures, mainly due to pulmonary vein thrombosis or obstruction and bronchial disruption or stenosis, a number of animals died in the early post-operative period due to lack of adequate blood replacement.

In a series of 32 consecutive animals, the operative mortality for pulmonary reimplantation was eight dogs in the first 48 hours $(25 \%) ; 12(37 \%)$ survived for long-term study. The remaining 12 animals died within four weeks, of pulmonary vein or atrial thrombosis (10), pneumonia (1). and stricture of the left main bronchus (1). Bronchospirometry was always carried out before and after each operation. This investigation included a test for the presence of the Hering-Breuer reflex, which was done by occluding one bronchus at the peak of inspiration. A positive test was indicated by interruption of the respiratory rhythm for at least two breaths. Only those animals showing satisfactory ventilation and oxygen uptake in the implanted lung were subjected to contralateral surgery.

Table I provides a detailed analysis of the 12 long-term survivors. It will be seen that three dogs underwent contralateral pneumonectomy, one of these having reimplantation of the upper lobe. All these dogs died of pulmonary oedema within three days. Four dogs had a staged resection of the right lung. One of these died after the first stage because of gangrene of the residual lobe. Another died 12 days after the final stage, having been in good health for 10 days. At the time of reimplantation, this animal was found to have obstruction of the superior pulmonary vein, and the upper lobe was removed. This animal survived for 12 days on a single reimplanted left lower lobe (estimated $25 \%$ of normal total lung capacity). At necropsy there were multiple granulomatous lesions in the lung together with terminal pulmonary oedema. The remaining two dogs survived these procedures and are in good health with adequate respiratory reserve up to eight months after the final operation. Figure 1 shows a dog six months after final operation.

Table II shows post-operative data 10 months after operation. There is no pulmonary hypertension or increased pulmonary resistance at this time.

TA B L E I

\begin{tabular}{|c|c|c|c|c|c|c|c|}
\hline \multirow[b]{2}{*}{$\begin{array}{l}\text { Dog } \\
\text { No. }\end{array}$} & \multirow{2}{*}{$\begin{array}{l}\text { Left Lung } \\
\text { Re- } \\
\text { implanted }\end{array}$} & \multirow[b]{2}{*}{$\begin{array}{l}\text { Survival } \\
\text { (mth.) }\end{array}$} & \multicolumn{3}{|c|}{ Contralateral Surgery } & \multirow[b]{2}{*}{ Cause of Death } & \multirow[b]{2}{*}{ Remarks } \\
\hline & & & $\begin{array}{c}\text { Total } \\
\text { Pneumonectomy }\end{array}$ & $\begin{array}{c}\text { Staged } \\
\text { Pneumonectomy }\end{array}$ & Survival & & \\
\hline 1 & 7.5.62 & 4 & & & & Distemper & $\begin{array}{l}\text { Partial stricture L. pulmon- } \\
\text { ary artery ; scar of } L \text {. } \\
\text { atrium obstructing upper } \\
\text { lobe pulmonary vein }\end{array}$ \\
\hline 2 & 30.7 .63 & $6 \cdot 5$ & & & & Sacrifice & $\begin{array}{l}\text { Partial stricture of } L \text {. main } \\
\text { bronchus, } L \text {. pulmonary } \\
\text { artery and } L \text {. atrium }\end{array}$ \\
\hline 3 & 14.9.62 & 6 & 8.3 .63 & & 54 hours & $\begin{array}{l}\text { Consolidated L. lung; } \\
\text { pulmonary oedema }\end{array}$ & \\
\hline $\begin{array}{l}4 \\
5\end{array}$ & $\begin{array}{r}1.10 .62 \\
4.2 .63\end{array}$ & $\begin{array}{l}5 \cdot 5 \\
+\end{array}$ & 25.10 .63 & & 32 hours & $\begin{array}{l}\text { Sacrifice } \\
\text { Pulmonary oedema }\end{array}$ & $\begin{array}{l}\text { Stricture L. main bronchus } \\
\text { Slow, forced respiratory } \\
\text { movements post-op. }\end{array}$ \\
\hline 6 & 31.12 .62 & + & & $\begin{array}{l}\text { 18.2.63 M.L. and } \\
\text { L.L. } \\
\text { 25.3.63 U.L. }\end{array}$ & + & & $\begin{array}{l}99 \% \text { arterial } \mathrm{O}_{2} \text { saturation } \\
\text { on } 6.11 .63\end{array}$ \\
\hline 7 & 4.1 .63 & + & & $\begin{array}{l}\text { 3.5.63 U.L. and } \\
\text { L.L. }\end{array}$ & 48 hours & Hypoxia & $\begin{array}{l}\text { Cyanosis + P.M. gangrene } \\
\text { R.M.L. }\end{array}$ \\
\hline 8 & 11.1 .63 & + & & $\begin{array}{l}\text { 25.2.63 R.U.L. } \\
\text { and R.L.L. } \\
\text { 22.3.63 R.M.L. }\end{array}$ & + & & $\begin{array}{l}5.4 .6392 \cdot 5 \% \text { arterial } \\
\text { saturation }\end{array}$ \\
\hline 9 & 14.1 .63 & + & $\begin{array}{l}11.3 .63 \mathrm{rt} . \\
\text { pneumonectomy } \\
\text { and replaced } \\
\text { R.U.L. }\end{array}$ & & 72 hours & Pulmonary oedema & $\begin{array}{l}\text { All strictures o.k.; slow, } \\
\text { deep respirations for first } \\
12 \mathrm{hr} \text {. }\end{array}$ \\
\hline 10 & 24.5 .63 & + & & & & & $\begin{array}{c}\text { Total stricture L. main } \\
\text { bronchus }\end{array}$ \\
\hline $\begin{array}{l}11 \\
12\end{array}$ & $\begin{array}{l}\text { 10.6.63 } \\
\text { Resection } \\
\text { L.U.L. } \\
7.10 .63\end{array}$ & & & $\begin{array}{l}\text { 23.8.63 R.L.L. } \\
\text { 9.9.63 R.U.L. } \\
\text { 11.10.63 R.M.L. }\end{array}$ & 12 days & $\begin{array}{l}\text { Pulmonary granulo- } \\
\text { mata ; pneumonia ; } \\
\text { ? pulmonary oedema }\end{array}$ & $\begin{array}{l}\text { Survival for } 12 \text { days on } \\
\text { single reimplanted } \\
\text { L.L. } \\
\text { Stricture L. main bronchus }\end{array}$ \\
\hline
\end{tabular}

M.L. = middle lobe $;$ L.L. = lower lobe $;$ U.L. = upper lobe ; R.U.L. = right upper lobe ; R.L.L. = right lower lobe ; R.M.L. $=$ right middle lobe; $+=$ indefinite survival. 


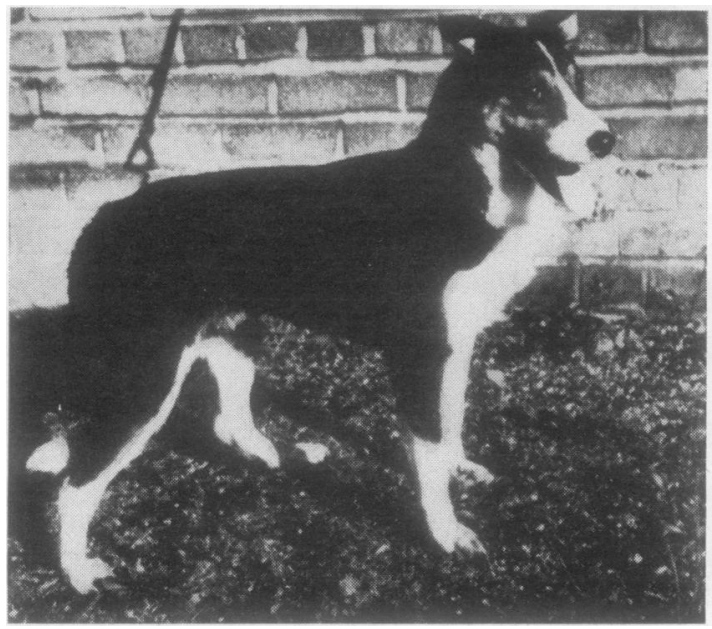

FIG. 1. Six months after left lung reimplantation and right staged pneumonectomy.

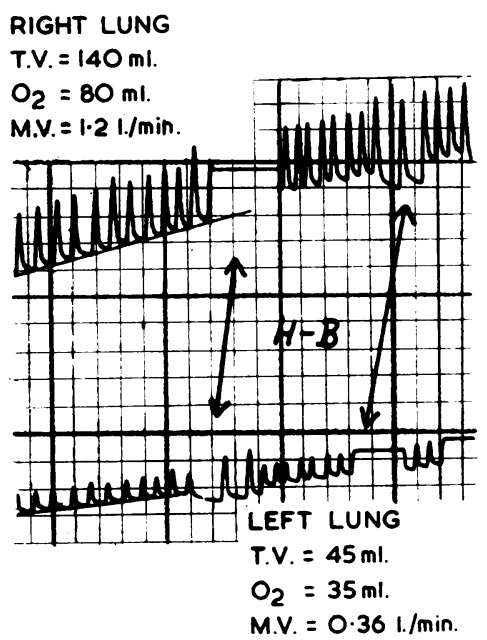

FIG. $2 \mathrm{a}$

RIGHT LUNG - T.V. $=130 \mathrm{ml}$

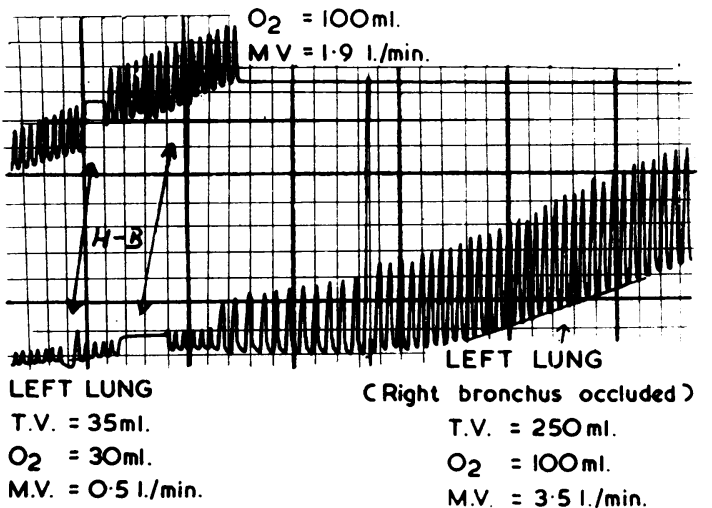

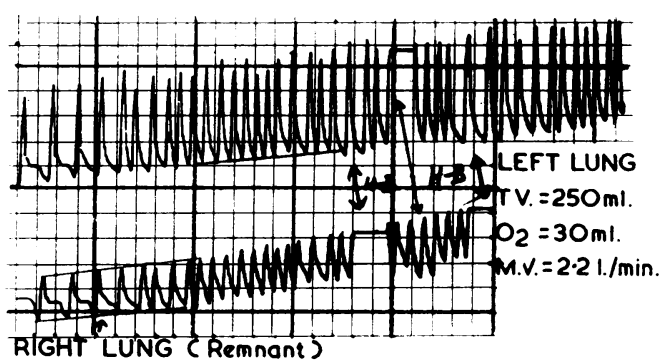

$T . V .=110 \mathrm{ml}$.

$\mathrm{O}_{2}=50 \mathrm{ml}$.

M.V. $=0.91 . / \mathrm{min}$.

FIG. 2c

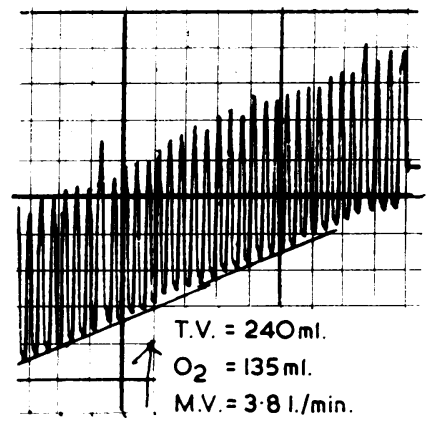

FIG. 2d

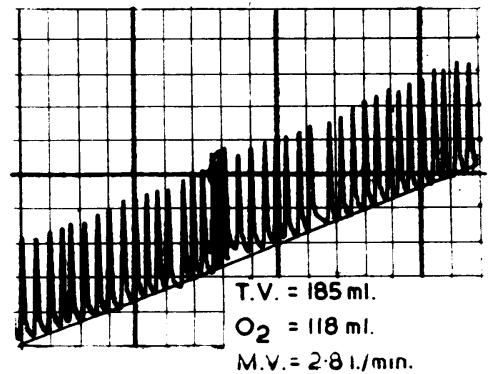

FIG. 2e

FIG. 2. (a) Preliminary bronchospirogram. $(H-B=H e r i n g$ Breuer reflex test. Note that the bronchus is occluded at the peak of inspiration.) (b) Bronchospirogram after left $\square$ lung reimplantation. Note absence of Hering-Breuer $\overline{0}$ reflex from left lung. (c) Bronchospirogram after resection $\vec{\Phi}$ of contralateral upper and lower lobes. (d) Spirogram of $\frac{\mathbb{D}^{+}}{4}$ single reimplanted left lung one week after completion $\varrho$ of right pneumonectomy. (e) Spirogram three months $\underset{<}{\sigma}$ after right pneumonectomy.

FIG. 2b 
T A B L E I I

\begin{tabular}{c|c|c|c|c|c}
\hline Dog & $\begin{array}{c}\text { Arterial* } \\
\mathbf{O}_{2} \\
\begin{array}{c}\text { Saturation } \\
(\%)\end{array}\end{array}$ & $\begin{array}{c}\text { Mean } \\
\mathbf{O}_{2} \\
\text { (ml. min.) }\end{array}$ & $\begin{array}{c}\text { Pulmonary } \\
\text { Artery } \\
\text { Pressure } \\
\text { (mm. Hg) }\end{array}$ & $\begin{array}{c}\text { Cardiac } \\
\text { Output } \\
\text { (l. min.) }\end{array}$ & $\begin{array}{c}\text { Pulmonary } \\
\text { Resistance } \\
\text { (units) }\end{array}$ \\
\hline 58 & 99 & 82 & 23 & 3 & $7 \cdot 5$ \\
61 & 95 & 86 & 26 & $2 \cdot 2$ & 11.7 \\
\hline
\end{tabular}

* Breathing $100 \%$ oxygen.

\section{DISCUSSION}

It is clear from these experiments that the dog can survive on a single reimplanted lung under certain conditions. The long interval between the reimplantation and final surgery raises the question whether regeneration of nerves has taken place. No Hering-Breuer reflex could be demonstrated at any stage after operation. What is perhaps of greater interest is the difference between immediate and staged resection of the healthy lung. Immediate resection was followed by early death from pulmonary oedema in all cases, which agrees with most published reports. Uncomplicated staged resection was successful in the two animals that completed the programme. While the numbers are small, the results seem conclusive when viewed in the light of other published series.

The concept of staged contralateral resection depends on the theory that the reimplanted lung is acting as a 'lazy lung,' an imprecise term for an unproved hypothesis. It is postulated that the reimplanted lung fails to ventilate and perfuse to its maximum because of a number of factors producing reduced compliance: $(a)$ post-thoracotomy fibrinous exudate and pleural reaction ; $(b)$ diffuse patchy atelectasis; and $(c)$ a loss of neural reflexes. With the presence of a normally ventilating lung, there is no impetus of hypoxic hyperventilation to overcome the post-operative changes that tend to persist. Such a lung is not capable of suddenly assuming the whole load of the circulation and ventilation, so total contralateral resection is followed by pulmonary hypertension and hypoxia with subsequent pulmonary oedema. If the contralateral lung is removed in stages, the hyperventilation induced as the normal lung volume is reduced is sufficient to force the reimplanted lung to resume its full expansion and adequate ventilation while there is still sufficient normal lung on the other side to maintain adequate oxygenation.

The concept of a 'lazy lung' is supported by the bronchospirographic tracings (Fig. 2). Figure 2a shows a normal pre-operative spirogram. After reimplantation, the tidal ventilation and oxygen uptake of the reimplanted left lung are greatly reduced, but on occluding the normal right bronchus there is a rapid increase of both ventilation and oxygen uptake. After resection of the right upper and lower lobes, the remaining middle lobe provides most of the oxygen uptake; but after its removal to complete the pneumonectomy the reimplanted lung shows adequate ventilation and oxygen uptake. It is proposed to undertake further studies to test the tentative hypothesis outlined above.

A remarkable feature of the operation of reimplantation is the apparently satisfactory metabolism of this complex organ with its tissue oxygen tension at that of mixed venous blood, owing to the failure to restore the bronchial arterial circulation. Furthermore, healing of the bronchial anastomosis appears to proceed normally in spite of the hypoxia of the distal bronchus that must be present, at least during the initial stages.

\section{CONCLUSION}

It is established here that the dog can survive on a single reimplanted lung. The quality of survival is satisfactory in that the animals are healthy and can exercise normally. This does not prove that the lung is functioning normally because we have shown that bitches can survive and produce and rear litters of pups on a single lobe of the right lung, i.e., an estimated $25 \%$ of normal lung volume. It is not possible at present to state to what extent, if any, nerve regeneration has taken place in these lungs. In our experience, disordered respiration and retention of secretions have not been serious problems. Slow, forced respirations occurred after contralateral pneumonectomy in one animal which died of pulmonary oedema 32 hours after operation. It is possible that this disordered respiration is a sign of pulmonary oedema rather than of pulmonary denervation.

\section{SUMMARY}

Twelve long-term survivors of pulmonary reimplantation in dogs were subjected to further study. Survival after contralateral pneumonectomy was achieved only when the contralateral resection was carried out in stages. Two long-term survivors on a single reimplanted lung remain in good health without apparent disability.

This work was made possible by grants from the Wellcome Foundation and the Medical Research Council of Ireland. We are indebted to Mr. K. Foran for the photographs. 


\section{REFERENCES}

Alican, F., and Hardy, J. D. (1963). Lung reimplantation. Effect on respiratory pattern and function. J. Amer. med. Ass., 183, 849.

Blumenstock, D. A., and Kahn, D. R. (1961). Replantation and transplantation of the canine lung. J. surg. Res., 1, 40.

Hardin, C. A., and Kittle, C. F. (1954). Experiences with transplantation of the lung. Science, 119, 97.

Juvenelle, A. A., Citret, C., Wiles, C. E., and Stewart, J. D. (1951). Pneumonectomy with replantation of the lung in the dog for physiologic study. J. thorac. Surg., 21, 111.
Linberg, E. J., Demetriades, A., Armstrong, B. W., and Konsuwan, N. (1961). Lung reimplantation in the dog. J. Amer. med. ass. 178, 486.

Nigro, S. L., Reimann, A. F., Mock, L. F., Fry, W. A., Benfield, J. R. and Adams, W. E. (1963). Dogs surviving with a reimplanted lung. Bronchospirometric and pulmonary artery pressure studies. Ibid., 183, 854 .

Portin, B. A. . Rasmussen, G. L., Stewart, J. D., and Andersen, M. N (1960). Physiologic and anatomic studies thirty-five months after successful replantation of the lung. J. thorac. Surg., 39, 380.

Yeh, T. J., Ellison, L. T., and Ellison, R. G. (1962). Functional evaluation of the autotransplanted lung in the dog. Amer. Rev. resp. Dis., 86, 791. 